It is clear from this work that thorough controlled and supervised washing by the wet method will not remove more than $50 \%$ of the original contaminants in soiled engineers' overalls. Indeed these figures may be on the liberal side as these experiments concerned contamination by clean solid-free oils. In ordinary practice the contaminants will be more tenacious due to the presence of finely divided particulate matter and will not be as easily washed out as the clean oils used in the experiments.

\section{Conclusions}

1. If engineering lubricants cannot be effectively removed from overalls by wet washing, then a supposedly clean garment worn by a worker at the beginning of each week will contain oil-contaminated capillaries in the fabric before he starts his work. Such fabrics may appear clean, and may even feel softer due to the presence of the oil, but this fabric condition is more rapidly recontaminated than a truly oil-free garment due to the capillary effect.

2. Since contamination of garments in engineering factories is always with oil associated with particulate matter, the residual oil which cannot be washed out will tend to make the abrasive particles more tenacious with the result that the hazard of skin disease by mechanical irritation is always present.

3. The weekly laundering of overalls to remove mineral oil contamination induces a false sense of security.

4. The only sure way of freeing overalls from oil and abrasive particles is by solvent extraction. Using perchlorethylene our laboratory work reveals that the cloth particles are completely free from oil at the end of the extraction cycle and this leads to the conclusion that this type of dry cleaning tends to be exhaustive as far as oil extraction is concerned.

Received for publication July 14, 1969.

\title{
Histamine in cereal dusts
}

\author{
P. J. NICHOLLS \\ University of Wales Institute of Science and Technology, Cardiff
}

\begin{abstract}
Nicholls, P. J. (1970). Brit. J. industr. Med., 27, 179-180. Histamine in cereal dusts. It has been found that workers exposed to cereal grain dusts may experience acute mild respiratory distress. An attempt has been made to explain this observation by examining the pharmacological activity of aqueous extracts of several cereal dusts from the holds of cargo ships. Histamine, but no other active agent, was found in the samples. It is unlikely that the concentration of histamine in these dusts is sufficient to cause respiratory distress in dockers unloading cereal grain cargoes.
\end{abstract}

Dockers unloading cargoes of cereal grain are often exposed to high concentrations of airborne cereal dust. It has been observed that several of these dusts can cause acute mild respiratory distress in the dockers and that inhalation of wheat dust produces a significant decrease in forced expiratory volume (Gandevia and Ritchie, 1966). It therefore appeared important to investigate the possibility that such effects are produced by a pharmacologically active agent in the dusts. 


\section{Materials and methods}

Samples of barley, maize, oat, and wheat dust that had settled on ledges or on the floor were collected, after unloading, from the holds of various cargo ships. Each sample was obtained from a different cargo vessel. Aqueous extracts of these dusts were prepared by macerating the material with Tyrode solution for 30 minutes and centrifuging. The pharmacological activity of the extracts was then examined using several animal preparations capable of detecting vasoconstrictor or smooth muscle contractor activity produced either by a direct mechanism or by the release of an active endogenous agent.

All the extracts caused contraction of the isolated guinea-pig ileum. The identity of this activity with that of histamine was shown by its specific antagonism by mepyramine and by other tests (Lloyd and Nicholls, 1964). No other direct-acting smooth muscle contractor or vasoconstrictor activity was detected using isolated preparations previously employed by Nicholls (1962), and the extracts did not cause the release of histamine, 5-hydroxytryptamine or kinin-like substances when incubated with animal and human lung (Nicholls, Nicholls, and Bouhuys, 1967). The histamine content of the extracts was determined by assay on the atropinized guinea-pig ileum.

\section{Results}

The results of the assay are presented in the Table and it may be seen that the histamine content of the dust samples varied widely. Although microscopical examination of the samples revealed the presence of fungal spores, a possible source of histamine (Langecker, 1934), there was no correlation between the abundance of spores and histamine concentration. As histamine was present in samples of cereal

\section{TABLE}

Histamine Content of Some Cereal Dusts ( $\mu$ g histamine $/ g_{\text {dust }}{ }^{1}$ )

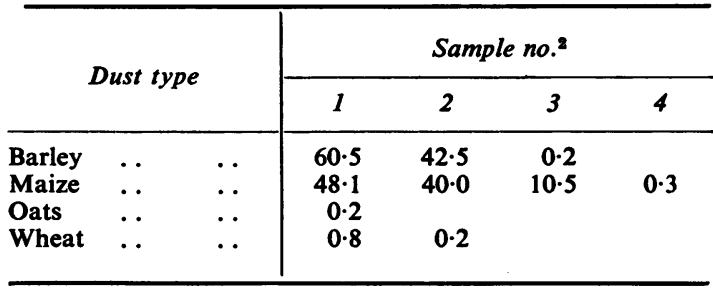

${ }^{1}$ Each result (as histamine base) is the mean of three determinations.

${ }^{2}$ Each sample collected from a different cargo ship. grains washed free of fungal spores $(0.2$ and 29.0 $\mu \mathrm{g}$ histamine/g of wheat and barley grain respectively) it would appear that the results represent the true histamine content of the cereals. The variation between samples from a single cereal type could be due either to the samples being non-representative or to the effect of the different environmental conditions under which the cereal plants were cultivated.

\section{Discussion}

Histamine frequently occurs in cotton dusts in concentrations of about the same order as are found in these cereal dusts (Nicholls, 1962 and unpublished observations). As the changes in pulmonary function observed after inhalation of high airborne concentrations of such cotton dusts are unrelated to the histamine present in the dust (Bouhuys and Nicholls, 1967), it is unlikely that this amine in the cereal dusts contributes to the respiratory distress experienced by the dockers.

Thus there is no pharmacological evidence to suggest that cereal dusts possess an effective agent capable of causing bronchoconstriction on inhilation by either direct or indirect means. It is possible that a non-specific mechanism, similar to that involved in the changes in lung function seen after inhalation of chemically inert dusts (Dubois and Dautrebande, 1958), is responsible for the effects observed in dockers unloading cereal cargoes.

The author is indebted to Drs. J. M. Jackson and R. K. Phillips for collecting the dust samples and to the Medical Research Council for financial assistance.

\section{References}

Bouhuys, A. and Nicholls, P. J. (1967). The effect of cotton dust on respiratory mechanics in man and in guinea pigs. In Inhaled Particles and Vapours. II. Ed. Davies, C. N., Pp. 75-83. Pergamon, Oxford.

Dubois, A. B. and Dautrebande, L. (1958). Acute effects of breathing inert dust particles and of carbachol aerosol on the mechanical characteristics of the lungs in man. Changes in response after inhaling sympathomimetic aerosols. J. clin. Invest., 37, 1746-1755.

Gandevia, B. and Ritchie, R. (1966). Relevance of respiratory symptoms and signs to ventilatory capacity changes after exposure to grain dust and phosphate rock dust. Brit. J. industr. Med., 23, 181-187.

Langecker, H. (1934). Zur Pharmakologie des Maisbrandes. Med. Klin., 30, 643.

Lloyd, G. R. and Nicholls, P. J. (1964). The presence of histamine in the cotton plant. J. Physiol., 172, 56-57P.

Nicholls, P. J. (1962). Some pharmacological actions of cotton dust and other vegetable dusts. Brit. J. industr. Med., 19, 33-41.

, Nicholls, G. R., and Bouhuys, A. (1967). Histamine release by Compound $48 / 80$ and textile dusts from lung tissue in vitro. In Inhaled Particles and Vapours. II. Ed. Davies, C. N., Pp. 69-74. Pergamon, Oxford.

Received for publication September 14, 1969. 